\title{
Patogenicidade de Alternaria cichorii sobre Espécies da Família Asteraceae no Brasil
}

\author{
Milton L. Paz Lima1, Ailton Reis ${ }^{2} \&$ Carlos A. Lopes ${ }^{2}$ \\ ${ }^{1}$ Universidade de Brasília, Departamento de Fitopatologia, Cx. Postal 4457, CEP 70910-900, Brasília, DF; ${ }^{2}$ Embrapa Hortaliças, \\ Cx. Postal 218, CEP 70359-970, Brasília, DF, e-mails: fitolima@unb.br; ailton@cnph.embrapa.br.
}

(Aceito para publicação em 08/08/2003)

Autor para correspondência: Milton L. Paz Lima

PAZ LIMA, M.L., REIS, A. \& LOPES, C.A. Patogenicidade de Alternaria cichorii em espécies da família Asteraceae no Brasil. Fitopatologia Brasileira 28:682-685. 2003.

\section{RESUMO}

Em 2001, plantas de chicória (Cichorium endivia) originárias do município de Catalão-GO apresentando sintomas de manchas e queima foliar foram recebidas na Clínica Fitopatológica da Embrapa Hortaliças $(\mathrm{CNPH})$. Tecidos submetidos à câmara úmida produziram esporulação fúngica, de onde foi obtida cultura monospórica em BDA + cloranfenicol. Para o teste de patogenecidade, o fungo foi multiplicado em meio de cultura suco de tomate ágar (ST) e inoculado em plantas de chicória da cultivar comercial AG-3804, em casa-devegetação. Após dez dias de incubação, verificou-se nas plantas inoculadas a presença de sintomas, semelhantes àqueles observados inicialmente. O patógeno foi reisolado a partir destas lesões, completando os postulados de Koch. Em seguida, visando testar a possibilidade deste patógeno infetar outras plantas da família Asteraceae, conídios produzidos em ST e atomizados em plantas de alface (Lactuca sativa) (três variedades), almeirão (Cichorium intybus) (duas variedades), Catalonha (Cichorium intybus) folha fina, serralha (Sonchus oleraceus) e uma outra variedade de chicória. Houve infecção em todas as plantas inoculadas, sendo que os sintomas variaram nas espécies e nas variedades testadas. Em chicória os sintomas surgiram mais cedo e se desenvolveram rapidamente. $O$ fungo foi caracterizado morfológica e morfometricamente permitindo identificá-lo como sendo Alternaria cichorii. Não se encontra registro desta espécie de Alternaria infetando plantas da família Asteraceae no Brasil. Neste trabalho relata-se pela primeira vez, a ocorrência de $A$. cichorii infetando chicória no Brasil e o potencial deste fungo como patógeno de outras espécies da família Asteraceae.

Palavras-chave adicionais: etiologia, chicória, Cichorium spp., alface.

\section{ABSTRACT}

Pathogenicity of Alternaria cichorii in species of the family Asteraceae

Endive plants (Cichorium endivia) from Catalão city, in the state of Goiás, Brazil that presented leaf spots, were examined in 2001 at the Embrapa Hortaliças (Embrapa Research Center for Vegetable Crops), Plant Disease Clinic. A single spore culture of a fungus of the genus Alternaria was obtained in PDA. The isolate was cultivated on tomato juice agar and conidia was used for inoculating endive plants $\left(10^{5}\right.$ conidia/ml) under greenhouse conditions. After incubation (ten days) symptoms similar to the ones originally observed were detected on the inoculated plants. The fungus was reisolated from those plants and Koch's postulates were carried out. The Pathogenicity of the fungus was also tested on other plants from the Asteraceae family such as lettuce (Lactuca sativa) (three cultivars), chicory (two cultivars), Catalonha (Cichorium intybus), annual sowthistle (Sonchus oleraceus) (weed species) and endive (control). The fungus infected all inoculated plants, but disease symptoms varied on each one. Symptoms started sooner and developed much more rapidly on endive plants. The pathogen was characterized morphologically and morphometrically and identified as Alternaria cichorii. Another Alternaria species (A. sonchi) was reported on endive in the States of São Paulo and Minas Gerais. This paper reports for the first time an occurrence of $A$. cichorii as a pathogen of endive in Brazil and discusses the possibility of infection in other Asteraceae plants.
A chicória (Cichorium endivia L.), popularmente conhecida por chicória de cabeça, escarola, entre outros, é uma hortaliça anual de ciclo curto, pertencente à família Asteraceae, cultivada em quase todas as regiões do Brasil, principalmente nos períodos de fevereiro a novembro na Região Sul, e o ano todo nas demais regiões do país (Filgueira, 2000). Muitos autores confundem a designação da espécie de chicória com a de almeirão (Cichorium intybus L.), conhecido, também, por catalonha, radicchio, entre outros.

O gênero Alternaria apresenta um grande número de espécies, com mais de 40 delas relatadas como patógenos de plantas (Rotem, 1994). A espécie Alternaria cichorii Nattrass está associada principalmente ao almeirão (Nattrass, 1937; Georghiou \& Papadopoulos, 1957; Patidou, 1973; Shaw, 1984; Saini et al., 1990; David, 1995; Simmons, 1997; Koike \& Butler, 1998; SBML - http:Innt.ars-grin.gov) e à alface (Lactuca sativa L.) (David, 1995; Koike \& Butler, 1998), embora exista um relato em feijão (Phaseolus vulgaris L.) (Mendes et al., 1998).

A chicória tem sido citada como hospedeira de espécies do gênero Alternaria, em índices de doenças de plantas nos Estados Unidos (Alfieri Jr. et al., 1984; Farr et al., 1989), Brasil (Viégas, 1946; Reifschneider et al., 1983; Mendes et al., 1998) e em Nova Guiné (Shaw, 1984). O CAB (1988) registra que $A$. cichorii é o agente causal da alternariose de Cichorium spp. 
Viégas (1946) descreveu a ocorrência de A. sonchi Davis \& Elliott nos Estados de Minas Gerais e São Paulo infetando folhas de chicória, enquanto que Simmons (1997) fez a descrição de A. sonchi nos EUA citando como hospedeiras Sonchus asper (L.) Hill e serralha (S. oleraceus L.). Pinto et al. (1995) relataram que existem poucos trabalhos relacionados a doenças fúngicas em chicória, citando como agente causal da alternariose da chicória no Brasil A. sonchi.

O objetivo do trabalho é relatar a ocorrência e patogenicidade de A. cichorii sobre chicória e o potencial de outras espécies da família Asteraceae como hospedeiras deste patógeno.

Folhas retiradas de plantas de chicória, produzidas em Catalão-GO e que apresentavam manchas necróticas e queima foliar (Figura 1A), foram submetidas à câmara úmida no Laboratório de Fitopatologia da Embrapa Hortaliças. Após 24 h, as lesões foram observadas sob microscópio estereoscópico, quando se detectou a presença de esporulação fúngica. Montaram-se lâminas semi-permanentes e observou-se ao microscópio composto que se tratava de uma espécie de Alternaria. As estruturas do fungo fixadas em lâmina semipermanentes foram fotografadas em microscopia de campo luminoso e contraste de fase. Alguns destes esporos foram transferidos, isoladamente, para placas de Petri contendo o meio de cultura BDA + cloranfenicol. Esporos de uma das colônias resultantes do crescimento fúngico foram transferidas para outras placas de BDA, obtendo-se assim cultura pura e monospórica do patógeno.

O fungo foi transferido para meio de suco de tomate ágar (ST) e incubado no escuro por dez dias a $25^{\circ} \mathrm{C}$, visando sua esporulação. Após isto, foi preparada uma suspensão de esporos na concentração de $10^{5}$ conídios $/ \mathrm{ml}$, que foi pulverizada sobre dez plantas de chicória (AG-3804) em casa de vegetação, permanecendo em câmara úmida por $48 \mathrm{~h}$. Dez plantas foram pulverizadas com água (testemunhas). Dez dias após a inoculação, folhas apresentando sintomas da doença foram submetidas a câmara úmida para esporulação e reisolamento do fungo.

Prepararam-se lâminas semi-permanentes com estruturas fúngicas para observação e registro em microscópio composto. Cerca de 50 conídios foram medidos quanto ao comprimento e maior largura, comprimento de bico e dimensões do conidióforo. Como complemento, foram observados o número de septos longitudinais e transversais e número de bicos (rostros). De acordo com as características morfológicas estudadas, identificou-se o patógeno comparando-o com a descrição de Simmons (1997).

Noutro teste, realizado em casa de vegetação (tipo 'Vander Hoeven'), visou-se verificar o potencial do isolado como patógeno de três cultivares de alface ('Tainá' - Sakata, 'Madona' - Horticeres e 'AG-819'), duas de almeirão ('Radiche Folhas' - Feltrin e 'Pão de Açúcar' - Ouro Flora), Catalonha ('Folha Fina' - Ouro Flora), serralha (obtida no campo da Embrapa Hortaliças) e uma variedade de chicória ('Escarola Lisa' - Isla). O preparo de inóculo e inoculação foram feitos conforme descrito anteriormente, sendo inoculadas seis plantas de cada espécie e/ou cultivar e duas de cada pulverizadas apenas com água (testemunhas). A avaliação da incidência (número de folhas com sintoma/número de folhas total) foi feita aos 1, 3 e 9 dias após a inoculação. O tipo de sintoma conferido em cada hospedeira foi descrito aos nove dias após a inoculação (Tabela 1), e finalmente classificou-se os materiais em dois grupos (altamente suscetíveis - AS e moderadamente suscetíveis - MS) com base na coalescência das lesões e na severidade da doença.

Foi isolado um fungo de micélio castanho escuro e crescimento rápido em meio BDA. A colônia fúngica, quando observada ao microscópio estereoscópico, apresentava esporulação abundante, com conídios característicos do gênero Alternaria. Quando transferido para meio de suco de

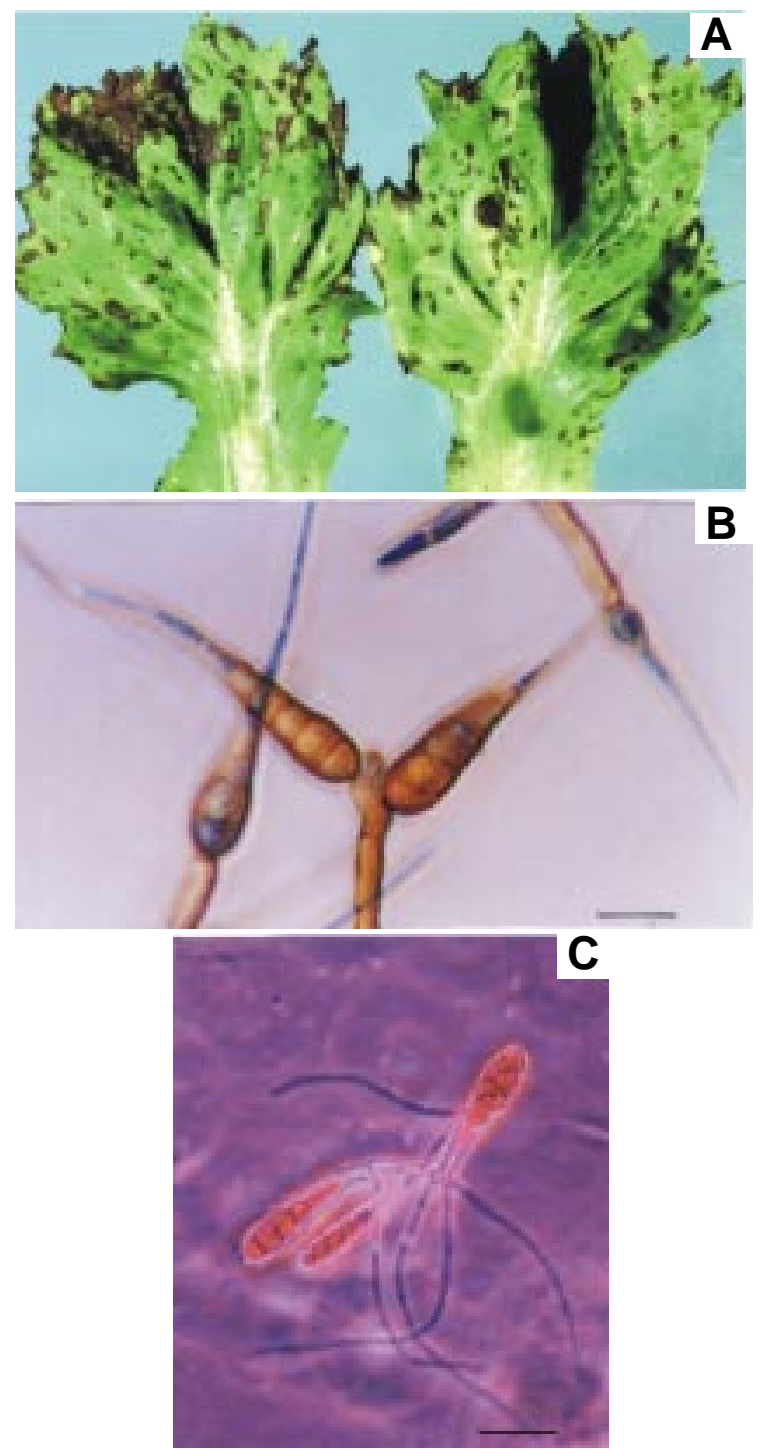

FIG. 1 - Etiologia de Alternaria cichorii em folhas de chicória (Cichorium endivia). A. Sintoma de mancha foliar não coalescente. B. conidióforo, célula conidiogênica e conídios em microscopia de campo luminoso $($ bar $=20 \mu \mathrm{m})$. C. ramificação do bico do conídio em microscopia de contraste de fase $(\mathrm{bar}=30 \mu \mathrm{m})$. 
TABELA 1 - Descrição dos sintomas nos hospedeiros de Alternaria cichorii nove dias após a inoculação

\begin{tabular}{ll}
\hline Hospedeira & Sintoma* \\
\hline Alface americana, & $\begin{array}{l}\text { Iniciam-se com pequenas lesões bem } \\
\text { distribuídas de cor alaranjada, finalizando } \\
\text { com coalescência marginal das lesões }\end{array}$ \\
Alface lisa & $\begin{array}{l}\text { Manchas de tamanho irregular, inicial- } \\
\text { mente alaranjadas brilhantes, avançando } \\
\text { para acinzentadas, havendo coalescência } \\
\text { com necrose marginal }\end{array}$ \\
Almeirão radichie & $\begin{array}{l}\text { Manchas circulares pontuais a oblongas, } \\
\text { com bordos avermelhados }\end{array}$ \\
Almeirão pão de & $\begin{array}{l}\text { Lesões com bordos avermelhados bem } \\
\text { distribuídas, não havendo coalescência das } \\
\text { lesões }\end{array}$ \\
Catalonha folha fina & $\begin{array}{l}\text { Lesões com bordos avermelhados bem } \\
\text { distribuídas, não havendo coalescência das } \\
\text { lesões }\end{array}$ \\
Chicória & $\begin{array}{l}\text { Iniciam-se com pequenas lesões escuras de } \\
\text { aspecto úmido, as quais avançam para } \\
\text { lesões necróticas e coalescem tomando } \\
\text { toda a área foliar }\end{array}$ \\
Serralha & $\begin{array}{l}\text { Lesões com bordos arroxeados, próximas } \\
\text { da nervura central }\end{array}$
\end{tabular}

*As dimensões das manchas foliares tiveram variações de 3-20 mm de diâmetro quando se encontravam isoladas (não confluentes).

tomate e 24 h de escuro, a esporulação era intensa e a coloração da colônia mais escura do que em BDA.

No teste de patogenicidade sobre chicória, obtiveramse sintomas da doença três dias após a inoculação, caracterizados por pequenas manchas necróticas, circulares a oblongas (3 a 20 mm de diâmetro) e centro mais claro (Figura 1A). Estas manchas foram se expandindo até a coalescência, tornando-se semelhantes àquelas observadas na planta recebida para diagnose. Com a evolução da doença, houve uma queima total das folhas mais velhas. As plantas testemunhas continuaram assintomáticas. Das folhas afetadas, o fungo foi reisolado em cultura pura, sendo a colônia e estruturas fúngicas iguais à cultura original. Com estes resultados completaram-se os postulados de Koch e confirmou-se a patogenicidade do fungo sobre chicória. Mais recentemente, obtiveram-se outros três isolados do patógeno, sendo um de plantas de chicória cultivadas em Brasília, um de semente comercial e outro de plantas oriundas de Paranaguá-PR. A patogenicidade destes isolados foi testada em chicória (AG-3804) e foi positiva para os três.

O patógeno apresentava conídios escuros, eusseptados, distosseptados, em sua maioria solitários, de formato reto ou ligeiramente curvados, fusiformes a obclavados, com quatro-nove septos transversais, zero-quatro septos longitudinais, com dimensões de 46-79(59) x 10-16(12) $\mu \mathrm{m}$, não ramificados, com leve constrição transversal e um bico que se estreita na extremidade terminal, podendo ramificar-se de dois a três (Figura 1C); células conidiogênicas terminais, simples a geniculadas, apicais, espessadas, de crescimento indeterminado (Figura 1B); conidióforos em geral escuros, lisos, com crescimento simpodial, medindo 41-128 (73) $\mu \mathrm{m}$ (Figura 1B). A conidiogênese é enteroblástica politrétrica como na descrição de A. cichorii encontrado em Koike \& Butler (1998). Quando cultivado em meio de cultura, o fungo apresenta uma ramificação da porção proximal do conídio, denominada bico (rostro) do conídio, sendo esta uma evidência também descrita por Koike \& Butler (1998). Ao comparar as características morfológicas acima com as características descritas por Simmons (1997), identificou-se como agente causal da queima das folhas da chicória a espécie $A$. cichorii.

Foram observados sintomas de manchas foliares em todas as plantas inoculadas, sendo que em chicória iniciaram $24 \mathrm{~h}$ após a inoculação, na forma de pequenas pontuações. Com três dias, já se observava pequenas lesões (manchas necróticas) em chicória. Sendo assim, nas condições experimentais, o período de incubação foi de apenas de três dias (Tabela 1). O fato de a chicória ter sido a hospedeira onde o patógeno foi mais agressivo é uma evidência que esta seja seu hospedeiro preferencial. As plantas testemunhas permaneceram assintomáticas. O reisolamento de $A$. cichorii comprovou ser ela a responsável pelos sintomas em todas as plantas inoculadas. Assim este fungo, além de já ser um problema para chicória, é patogênico às outras plantas testadas e pode, potencialmente, afetar outras hospedeiras da mesma família. Já havia relatos de $A$. cichorii infetando outras hospedeiras diferentes de chicória, tal como feijão, almeirão e alface (Nattrass, 1937; Georghiou \& Papadopoulos, 1957; Patidou, 1973; Parmar et al., 1983; Shaw, 1984; Saini et al., 1990; David, 1995; Simmons 1997; Mendes et al., 1998; Koike \& Butler, 1998; SBML-http:IInt.ars-grin.gov).

No Brasil, o registro da alternariose da chicória referese à espécie $A$. sonchi como o agente causal. No entanto, as características descritas para esta espécie de Alternaria não se enquadram àquelas do isolado encontrado neste trabalho, pois este apresenta conídios com septos longitudinais e muitos transversais, enquanto que $A$. sonchi apresenta somente septos transversais (Viégas, 1946) ou raros septos longitudinais (Ellis, 1971), não apresentando apêndices no conídio (Viégas, 1946). As hospedeiras de A. sonchi descritas por Viégas (1946), foram chicória, alface e zínia (Zinnia elegans Jacq.), nos estados de MG, SP e GO. Encontram-se registradas, na literatura internacional, duas possíveis espécies de Alternaria infetando chicória, A. cichorii (Elia, 1968; Ellis, 1971; Vakalounakis \& Christias, 1981; Shaw 1984; David, 1995; Koike \& Butler, 1998) e A. sonchi (Viégas, 1946; Alfieri Jr. et al., 1984; Pinto et al. 1995; Mendes et al., 1998;). Também, Koike \& Butler (1998), na Califórnia, registraram a ocorrência de $A$. cichorii em almeirão, chicória e alface, enquanto que Parmar et al. (1983) relataram na Índia a ocorrência de $A$. cichorii em almeirão.

A variabilidade quanto à intensidade da doença na planta, a coalescência de lesões e em consequência do desenvolvimento visual da doença (severidade), permitiu que fosse 
Patogenicidade de Alternaria cichorii sobre espécies da família...

criado uma classificação dos genótipos em altamente suscetíveis e moderadamente suscetíveis. Todos os materiais foram suscetíveis, não havendo nenhum material resistente, existindo no entanto diferenças quanto ao desenvolvimento da doença que em alguns é mais lenta (almeirão e serralha) e em outros é mais rápida (chicória e alface) (Tabela 2 ).
Não se encontrou registro de $A$. cichorii em almeirão e tampouco em serralha no Brasil. A espécie de Alternaria infetando alface no Brasil foi registrada como A. sonchi por Pinto et al. (1995) e Viégas (1946). Sendo assim, aparentemente este é o primeiro registro da infecção de $A$. cichorii em serralha, almeirão, alface e chicória no Brasil.

TABELA 2 - Incidência de alternariose causada por Alternaria cichorii (número de folhas doentes $/ n^{\circ}$. de folhas totais) aos três e nove dias após a inoculação (DAI)*

\begin{tabular}{|c|c|c|c|c|c|c|c|c|c|c|c|c|}
\hline \multicolumn{2}{|c|}{ Espécie Hospedeira } & \multicolumn{5}{|c|}{3 DAI } & \multicolumn{5}{|c|}{9 DAI } & \multirow{2}{*}{ Classe } \\
\hline Nome comum & Nome científico & $\mathrm{P}_{1}$ & $\mathrm{P}_{2}$ & $\mathrm{P}_{3}$ & $\mathrm{P}_{4}$ & $\mathrm{P}_{5}$ & $\mathrm{P}_{1}$ & $\mathrm{P}_{2}$ & $\mathrm{P}_{3}$ & $\mathrm{P}_{4}$ & $\mathrm{P}_{5}$ & \\
\hline Alface Americana Madona & Lactuca sativa & $5 / 5$ & $5 / 5$ & $4 / 4$ & $3 / 3$ & $4 / 4$ & $5 / 6$ & $3 / 5$ & $3 / 4$ & $5 / 6$ & $2 / 3$ & AS \\
\hline Alface americana Tainá & L. sativa & $3 / 3$ & $3 / 3$ & $3 / 3$ & $3 / 3$ & $3 / 3$ & $4 / 4$ & $5 / 5$ & $4 / 4$ & $3 / 3$ & $3 / 3$ & AS \\
\hline Alface lisa & L. sativa & $5 / 5$ & $5 / 5$ & $6 / 6$ & $5 / 5$ & $6 / 6$ & $5 / 4$ & $4 / 4$ & $5 / 8$ & $4 / 5$ & $7 / 9$ & AS \\
\hline Almeirão radichie & Cichorium intybus & $3 / 5$ & $2 / 4$ & $3 / 4$ & $4 / 4$ & $4 / 4$ & $6 / 6$ & $3 / 3$ & $4 / 4$ & $7 / 7$ & $3 / 4$ & MS \\
\hline Almeirão Pão de açúcar & C. intybus & $1 / 4$ & $6 / 6$ & $5 / 5$ & $4 / 3$ & $4 / 5$ & $4 / 4$ & $5 / 5$ & $4 / 4$ & $4 / 4$ & $5 / 5$ & MS \\
\hline Catalonha folha fina & C. intybus & $1 / 6$ & $1 / 4$ & $2 / 5$ & $4 / 5$ & $5 / 5$ & $4 / 6$ & $4 / 5$ & $7 / 7$ & $6 / 6$ & $5 / 5$ & MS \\
\hline Chicória & C. endivia & $3 / 3$ & $3 / 3$ & $3 / 3$ & $3 / 2$ & $3 / 2$ & $5 / 5$ & $3 / 3$ & $3 / 3$ & $4 / 4$ & $3 / 3$ & $\mathbf{A S}$ \\
\hline Serralha & Sonchus oleraceus & $1 / 4$ & $1 / 4$ & 0 & 0 & 0 & $4 / 5$ & $2 / 6$ & $4 / 6$ & $4 / 5$ & $4 / 5$ & MS \\
\hline
\end{tabular}

$* \mathrm{P}_{1,3,4,5}=$ planta número 1,2,3,4,5; Classes de reação - AS. altamente suscetíveis - lesões se coalescem, MS. moderadamente suscetíveis - lesões não coalescem.

\section{LITERATURA CITADA}

ALFIERI JR, S.A., LANGDON, K.R., WEHLBURG, C. \& KIMBROUGH, J.W. Index of Plant Diseases in Florida. Florida Department of Agriculture \& Consumer Services. USA. Bulletin 11. 1984.

$\mathrm{CAB}$ International course on the identification of fungi of agricultural importance: Alternaria and Cladosporium. CAB/IMI. Kew. Surrey, 1988.

ELIA, M. Alternaria porri (Ell.) Saw., f.sp. cichorii (Nattr.) Schmidt su endivia e cicoria in Puglia (Italia). Phytopathologia Mediterranea 7:7-14. 1968

ELLIS, M.B. Dematiaceous Hyphomycetes. Kew, Commonwealth Mycological Institute, 1971.

FARR, D.F., BILLS, G.F., CHAMURIS, G.P. \& ROSSMAN, A.Y. Fungi on Plants and Plant Products in the United States. St Paul. Minnesota, USA APS, 1989.

FILGUEIRA, F.A.R. Novo manual de olericultura - agrotecnologia moderna na produção e comercialização de hortaliças. $1^{\mathrm{a}}$ ed. Viçosa: Editora UFV, 2000.

GEORGHIOU, G.P. \& PAPADOPOULOS, C. A second list of Cyprus fungi. Government of Cyprus. Departament of Agriculture.1957.

KOIKE, S.T. \& BUTLER, E.E. Leaf spot of radicchio caused by Alternaria cichorii. Plant Disease 82:448. 1998. (Note)

MENDES, M.A.S., SILVA, V.L., DIANESE, J.C., FERREIRA,
M.A.S.V., SANTOS, C.E.N., GOMES NETO, E., URBEN, A.F. \& CASTRO, C. Fungos em plantas no Brasil. Brasília. Embrapa-SPI/ Embrapa Cenargen. 1998.

NATTRASS, R.M. A first list Cyprus fungi. Nicosia. 1937.

PARMAR, S.M.S., TANEJA, S., JAIN, B.L. \& WILLIAMSON, D. Biochemical changes in Cichorium intybus infected by Alternaria cichirii. Indian Phytopathology 36:680-682. 1983.

PATIDOU, M.E. Fungus host index of Greece. Benaki Phytopathology Institute, Kiphissia, Athens, 1973.

PINTO, C.M.F., PAULA JÚNIOR, T.J. \& MIZUBUTI, E.S.G. Doenças causadas por fungos em alcachofra, alface, chicória, morango e quiabo. Informe Agropecuário 17:5-13. 1995.

REIFSCHNEIDER, F.J.B., SIQUEIRA, C.B. \& CORDEIRO, C.M.T. Índice de doenças de hortaliças no Brasil - bactérias e fungos. Brasília. Embrapa-CNPH. vol. 1. 1983.

ROTEM, J. The genus Alternaria: biology, epidemiology and pathogenicity. St. Paul. APS Press, 1994.

SAINI, S.S., KUMARI, S. \& ATRI, N.S. Some new records of Alternaria Nees:Fr from Punjab. Indian Journal of Mycology and Plant Pathology 20:74-75. 1990.

SHAW, D.E. Microorganisms in Papua New Guinea. Department of Primary Industry Research Bulletin 33:344. 1984.

SIMMONS, E.G. Alternaria themes and variations (151-223). Mycotaxon. 65:1-91. 1997.

VIÉGAS, A.P. Alguns fungos do Brasil XIII: Hifomicetos. Bragantia 6:353-356. 1946. 